Cross-cultural examination of different personality pathways to alcohol use and misuse in emerging adulthood

\title{
Laura Mezquita*
}

Department of Basic and Clinical Psychology and Psychobiology

Universitat Jaume I, Castelló de la Plana, Castellón, Spain

Centre for Biomedical Research Network on Mental Health (CIBERSAM)

Instituto de Salud Carlos III, Castellón de la Plana, Spain

Adrian J. Bravo

Center on Alcoholism, Substance Abuse, and Addictions

University of New Mexico, USA

Generós Ortet

Department of Basic and Clinical Psychology and Psychobiology

Universitat Jaume I, Castelló de la Plana, Castellón, Spain

Centre for Biomedical Research Network on Mental Health (CIBERSAM)

Instituto de Salud Carlos III, Castellón de la Plana, Spain

Angelina Pilatti

Facultad de Psicología

Universidad Nacional de Córdoba, Argentina

Instituto de Investigaciones Psicológicas, IIPSI, Unidad Ejecutora CONICET. Córdoba, Argentina

CIPSI Grupo Vinculado CIECS-UNC-CONICET. Córdoba, Argentina

Matthew R. Pearson

Center on Alcoholism, Substance Abuse, and Addictions

University of New Mexico, USA

Manuel I. Ibáñez

Department of Basic and Clinical Psychology and Psychobiology

Universitat Jaume I, Castelló de la Plana, Castellón, Spain

Centre for Biomedical Research Network on Mental Health (CIBERSAM)

Instituto de Salud Carlos III, Castellón de la Plana, Spain

*Correspondence about this article should be addressed to Laura Mezquita at the Department of Basic and Clinical Psychology and Psychobiology, Universitat Jaume I, Av. de Vicent Sos Baynat, s/n, 12071 Castellón, Spain. L. Mezquita can also be contacted by fax (+34 96472 9267), phone (+34 96472 9704) or e-mail:

lmezquit@uji.es

Supplementary material can be found by accessing the online version of this paper at http://dx.doi.org and by entering doi: ... 


\begin{abstract}
Background: Previous research has identified different, but not mutually exclusive, etiological pathways (i.e., the positive affect regulation pathway, the negative affect regulation pathway and the deviance proneness pathway) to alcohol use and misuse in which personality characteristics play a key role. Objectives: The present study aimed to simultaneously and cross-culturally examine all these personality pathways to alcohol use in a large sample of young adult drinkers $(N=1280)$ from the US, Argentina and Spain. Method: Structural equation modeling was conducted to test the models. Multigroup models were conducted to test model invariance across countries and gender groups. Results: In the whole sample, low conscientiousness and extraversion were related to alcohol outcomes through enhancement drinking motives (i.e., positive affect regulation pathway), low emotional stability was related through coping drinking motives (i.e., negative affect regulation pathway), and low conscientiousness and low agreeableness were related through antisocial behavior (i.e., deviance proneness pathway). The model was invariant between gender groups. Some minor, yet significant, differences across countries arose. Specifically, antisocial behavior was a significant mediator of the association between agreeableness and alcohol use, but only in the US subsample. Conclusions: The present findings suggest that risky-personality pathways for alcohol use and alcohol-related problems may be generalized across gender groups and cultures in young adults.
\end{abstract}

Keywords: personality, etiological pathways, alcohol, drinking motives, antisocial behavior, cross-cultural study 


\section{Introduction}

Alcohol use and misuse involve serious socio-economic and health problems (World Health Organization [WHO], 2014). Alcohol misuse is a leading cause of mortality worldwide (WHO, 2014b, 2013) as it has been associated with over 60 medical conditions (Room et al., 2005). In all age groups, the highest prevalence of alcohol misuse is found among emerging adults (U.S., Grant et al., 2016; Spain, National Plan of Drugs, 2015; Secretariat of Integral Policies on Drugs-Argentina, 2017). Alcohol use has also been estimated to be the highest risk factor for disabilityadjusted life years (DALYs) in this age group worldwide (Mokdad et al., 2016) and has been related to increased risk-taking, loss of control (i.e., drinking and driving, at-risk sexual behaviors), and occupational/academic impairment (Hingson et al., 2017; Pilatti et al., 2016). Effective prevention and intervention programs targeting problematic alcohol use could be devised/modified with a better understanding of the etiological pathways associated with alcohol use/misuse in young adults (Hawkins et al., 2002).

\subsection{Etiological Pathways to Alcohol Use}

In comprehensive terms, numerous social, biological and psychological variables impact alcohol use (Zucker, 2015; Zucker et al., 1994) via distinct, but not mutually exclusive, etiological pathway types: 1) positive regulation; 2) negative regulation; 3) deviance proneness; 4) pharmacological vulnerability (for an overview, see Sher, Grekin, \& Williams, 2005). The present study centers on three of the four pathway types (exception is pharmacological vulnerability).

\subsubsection{The Positive Affect Regulation Pathway}

The positive affect regulation pathway refers to drinking alcohol in order to experience positive alcohol reinforcement effects, for example, "because I like the feeling” or "because it's fun" (Sher et al., 2005). Within motivational models of alcohol 
(Cooper, 1994; Cox and Klinger, 2004, 1988), positive affect regulation is related to enhancement drinking motives (Cooper et al., 1992). Enhancement drinking motives have been related to drinking with friends at home or drinking at bars (Cooper, 1994), with same-sex friends (Cooper, 1994; Cooper et al., 1992), weekend drinking (Mezquita et al., 2011; Studer et al., 2014) and binge drinking (White et al., 2016). Cross-sectional (Adams et al., 2012; Caneto et al., 2014; Goldstein et al., 2010) and longitudinal (Vernig and Orsillo, 2015) studies have found an association between enhancement motives and alcohol-related problems, even though these associations seem mediated by alcohol use (Merrill, Wardell, \& Read, 2014; Mezquita, Stewart, \& Ruipérez, 2010). Additionally, multiple meta-analyses support an association between personality traits (e.g., impulsivity and extraversion) and alcohol use/misuse (Coskunpinar et al., 2013; Hakulinen et al., 2015; Kotov et al., 2010). Noteworthy, a number of studies, based on the Big Five Model of Personality, found that the associations involving extraversion and low conscientiousness with alcohol outcomes are fully or partially mediated by enhancement drinking motives (Kuntsche et al., 2008; Mezquita et al., 2014, 2010; Stewart et al., 2001). These findings support the existence of a positive affect regulation pathway, in which disinhibition and positive emotionality characteristics play a key role.

\subsubsection{The Negative Affect Regulation Pathway}

The negative affect regulation, or the internalizing, pathway (Kendler et al., 2016) builds on the "self-medication" or "tension reduction" hypotheses, in which drinking alcohol is mainly driven to diminish negative affect states, like anxiety or depression (i.e., "to cheer up when I am in a bad mood" or "to forget my worries") (Sher et al., 2005). Within motivational models of alcohol (Cooper, 1994; Cox \& Klinger, 1988, 1990), negative affect regulation is related to coping motives, which 
have been associated with drinking at home, drinking alone, heavy drinking (Mohr et al., 2005; O’Hara et al., 2014), and drinking during the weekdays (Studer et al., 2014). Further, both cross-sectional (Bravo, Pearson, Stevens, \& Henson, 2016; Bravo, Prince, \& Pearson, 2015; Mezquita et al., 2010) and longitudinal (Merrill et al., 2014; Mezquita et al., 2016; Vernig \& Orsillo, 2015) studies have found a robust link between coping motives and alcohol-related problems. Additionally, low emotional stability, or neuroticism, has been related to alcohol disorders and alcohol-related problems (Kotov et al., 2010; Ruiz et al., 2003). Coping motives appear to, at least partially, mediate these associations (Blevins et al., 2016; Mezquita et al., 2014, 2010; Stewart et al., 2001). These results support the relevance of a negative affect regulation pathway, in which neuroticism-related traits would play a prominent role.

\subsubsection{The Deviance Proneness Pathway}

In the externalizing (Kendler et al., 2016; Zucker, 2008) or deviance proneness (Finn et al., 2000; Sher et al., 2005) pathway, alcohol use is seen as an element, or symptom, of a more general, deviant, pattern rooted in former developmental stages. Recent longitudinal research further supports the existence of this pathway such that alcohol outcomes are related to drug use, parental alcohol use, childhood maltreatment, permissive parenting styles, affiliation with deviant peers, and also to other externalizing problems like antisocial behavior (Edwards et al., 2015; Kendler et al., 2016, 2011; Mezquita et al., 2014). Moreover, this pathway has been associated with deviance proneness traits such as low agreeableness, low conscientiousness, low socialization and high sensation-seeking (Edwards et al., 2015; Finn et al., 2000;

Kendler et al., 2011; Mezquita et al., 2015, 2014).

\subsection{Present Study and Hypotheses}

Despite compelling evidence supporting the proposed paths, very few studies 
have simultaneously examined these personality-related pathways. Based on Sher et al.'s model (2005), Mezquita and colleagues (2014) found significant prospective effects of childhood maltreatment and personality characteristics on alcohol use and alcohol-related problems via antisocial behaviors and drinking motives, further supporting the co-existence of the three pathways. The present study aimed at examining whether these findings, based on the Big Five Personality Framework, generalize to samples of young adults from diverse socio-cultural backgrounds (i.e., the US, Spain, and Argentina).

Based on former research (Blevins et al., 2016; Mezquita et al., 2010, 2014; Sher et al., 2005; Stewart et al., 2001), we hypothesized (see Supplementary Material [SM $\left.{ }^{1}\right]$ ) that neuroticism or low emotional stability will be mainly related to alcohol-related problems via coping drinking motives (i.e., the negative affect regulation pathway). Additionally, we expected that both low conscientiousness and extraversion will be associated with alcohol use via enhancement drinking motives (i.e., the positive affect regulation pathway) (Kuntsche et al., 2008; Mezquita et al., 2014, 2010; Stewart et al., 2001). We also anticipated links from low agreeableness and low conscientiousness to alcohol outcomes via antisocial behavior (i.e., the deviance proneness pathway) (Finn et al., 2000; Mezquita et al., 2014). Further, specific direct paths between the Big Five Personality Domains and alcohol outcomes were included in the model to test whether the mediation was partial or total ( $\left(\mathrm{see} \mathrm{SM}^{1}\right)$. Additionally, we examined model invariance across gender.

College students from individualistic cultures (e.g., U.S.), compared to those from collectivistic cultures (e.g., Spain), tend to report higher levels of positive reinforcement motives; however, the rank order of endorsed drinking motives

\footnotetext{
${ }^{1}$ Supplementary material can be found by accessing the online version of this paper at http://dx.doi.org and by entering doi: ...
} 
(MacKinnon et al., 2017) and the associations between motives and alcohol outcomes across countries have been shown to be similar (Couture et al., 2017; Mezquita et al., 2016). Moreover, previous work supported these three etiological pathways in Spanish adults (Mezquita et al., 2014), and former research with UK and US populations evidenced internalizing (related to negative emotionality) and externalizing (related to disinhibition) pathways to alcohol use and problems (Edwards et al., 2015; Kendler et al., 2011). Taken together, we expected the proposed etiological pathways to be crossculturally invariant.

\section{Method}

\subsection{Participants and Procedure}

Participants were college students $(n=1864)$ enrolled in four universities (two located in the U.S., one in Argentina, and one in Spain) who completed an online survey about personality traits, personal mental health, and alcohol use behaviors (for further information about recruitment procedures and participant compensation, see Bravo et al., 2018a). Following previous research (Bravo et al., 2018b), and to capture a wide range of drinking behaviors, data from last-month drinkers (i.e., consumed alcohol at least one day in the previous month) were used in the present study. The final analytic sample comprised of 1280 students (U.S. sites combined, $n=673,70.72 \%$ females; Argentina, $n=332,53.92 \%$ females; Spain, $n=275,71.27 \%$ females $)$. Table 1 presents the demographics for the total sample and by country. Participants across all sites completed the same battery of measures using the Qualtrics software. The institutional review boards (or their international equivalent) at the participating universities approved the research.

\subsection{Measures}

\subsubsection{Personality Traits}


The Big Five Personality Trait Short Questionnaire (BFPTSQ; Morizot, 2014; Ortet et al., 2017) was used to assess five personality domains: openness, extraversion, emotional stability (or low neuroticism), agreeableness and conscientiousness. The BFPTSQ has 50 items that are answered on a 5-point response scale from 0 (totally disagree) to 4 (totally agree). The introduction sentence, "I see myself as someone who..." is shown at the top of every page.

\subsubsection{Drinking Motives}

Drinking motives were assessed using the Drinking Motives QuestionnaireRevised Short Form (DMQ-R SF; Kuntsche and Kuntsche, 2009; Mezquita et al., 2018) which comprises 12 items grouped in four dimensions: coping, enhancement, social and conformity motives. Participants indicate, using a 5-point response scale from 1 (almost never/never) to 5 (almost always/always), how often they drink for the reason specified in each item.

\subsubsection{Antisocial Social Behavior}

The Spanish Antisocial Behavior Scale (ABS; Mezquita et al., 2014) was used to assess antisocial behavior. It comprises 35 items (e.g. "I have broken, ripped, or damaged public properties", "I have used knives or sticks in fights") that describe different antisocial behaviors on a 4-point response scale from 1 (never/almost never) to 4 (very frequently/very often). Summing all answers provides a total score of antisocial behavior. Minor changes were made in the Castilian Spanish ABS version to ensure that all the items were suitable for the Argentinian sample (e.g., "coche" was changed to "auto" to respectively indicate "car" in Castilian Spanish and Argentinian Spanish). All measures but the ABS were available in English. Hence two psychologists, proficient in both English and Spanish, and with expertise in addictive behaviors and psychometrics, translated the original Spanish version into English. Next, a bilingual teacher, who was 
not familiar with the inventory, back translated this version into Spanish. Versions were compared and results revealed that the English version could be comparable to the original measure.

Examining measurement invariance of the ABS was not an aim of the present study; however, since the ABS has not been previously employed with U.S. populations, we examined differential item functioning (DIF, jMetrik software) of each item across countries to ensure the comparison of the total ABS scores across countries (Meyers, 2014). Of 105 comparisons, 98 items showed a negligible amount of DIF, six a moderate amount of DIF, and only one showed an SP-DIFF higher than .10 (an sPDIFF of .10 or higher denotes a large amount of DIF; Meyers, 2014) (complete results can be provided upon request).

\subsubsection{Alcohol Use}

The Daily Drinking Questionnaire (DDQ; Collins, Marlatt, Parks, \& Marlatt, 1985), and several other single-item measures, were used to measure alcohol use. Specifically, we measured volume of alcohol consumed during a typical week (based on how much alcohol was consumed, from Monday to Sunday, during a typical week of the last month), drinking frequency (number of days with alcohol use within the last 30 days), and binge drinking frequency (number of days they drank 4+/5+ SDUs [US and Argentina] or 5.5+/7+ [Spain] within a 2-hour period). Participants received a visual guide with typical drinks (specific to each country) to orient them how to estimate Standard Drink Units (SDUs). To calculate the total amount of alcohol consumed during a typical week, the total number of SDUs was converted into grams of alcohol considering that one SDU equals 14 grams in the US and Argentina (International Alliance for Responsible Drinking [IARD], 2016; National Institute on Alcohol Abuse and Alcoholism [NIAAA], 2015) and 10 grams in Spain (IARD, 2016; Rodríguez- 
Martos et al., 1999).

\subsubsection{Negative Alcohol-Related Consequences}

The 48-item Young Adult Alcohol Consequences Questionnaire (YAACQ; Read et al., 2006) was used to assess negative alcohol-related consequences at the US sites, and the 48-item Spanish version (S-YAACQ; Pilatti et al., 2016) in Argentina and Spain (after rewording some items into Castilian Spanish). Each item was scored scored to reflect the absence or presence of alcohol-related problems in the last 30 days $(0=n o, 1$ $=y e s)$. Total scores reflect the total number of negative consequences experienced within that period.

\subsection{Missing Data Imputation}

For each participant who answered more than $90 \%$ of all the questionnaires, the total score was calculated on each scale by a person mean imputation approach on each scale. Missing values only represented $0.14 \%$ of all the possible values (145 items $\mathrm{x}$ 1280 participants), which falls well within the cut-off recommended for this technique (Bentler, 2006). Despite our imputations, some missing values in the total scale scores included in the structural equation model were noted for 39 participants. So a maximum likelihood (ML) estimator for missing data was implemented (Muthén \& Muthén, 19982009).

\subsection{Statistical Analysis}

To test the proposed model (see $\mathrm{SM}^{1}$ ), structural equation modeling (Muthén \& Muthén, 1998-2009) was carried out using Mplus 5.21. To evaluate the overall model, model fit criteria suggested by $\mathrm{Hu}$ and Bentler (1999) were employed, including Tucker-Lewis Index $(\mathrm{TLI})>.95$, the Comparative Fit Index $(\mathrm{CFI})>.95$, Standardized

\footnotetext{
${ }^{1}$ Supplementary material can be found by accessing the online version of this paper

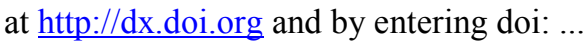


Root Mean Square Residual $(\mathrm{SRMR})<.06$. and Root Mean Square Error of Approximation $($ RMSEA) $<.08$. Multi-group analyses were run to test model invariance across both gender groups and countries. The chi-square difference test is widely used to examine model invariance, but is sensitive to sample size (Brown, 2015). Thus, we also examined any decrements in CFI and RMSEA ( $\triangle$ CFI should be $\leq .010$ to consider a model invariant, Cheung \& Rensvold, 2002; while $\triangle$ RMSEA ought to be $\leq .015$, Chen, 2007) across more and less constrained models as a test of invariance.

We examined the total, indirect and direct effects of each predictor variable on alcohol outcomes using bias-corrected bootstrapped estimates (Efron and Tibshirani, 1993) based on 10000 bootstrapped samples. This provides a powerful mediation test (Fritz and MacKinnon, 2007), and one that is robust to small deviations from normality (Erceg-Hurn and Mirosevich, 2008). To determine statistical significance, 99\% biascorrected bootstrapped confidence intervals not containing zero were used.

\section{Results}

For the total sample and across countries, Table 1 shows descriptive statistics and internal consistencies for all measures. All the internal consistencies ranged from adequate to excellent, and Cohen's $d$ (Cohen, 1992) showed that the differences in the mean levels of the scales among countries were relatively small. The only exception was the moderate difference found between U.S. and Spain on coping drinking motives (U.S. > Spain).

\subsection{Hypothesized Model}

The hypothesized model $\left(\mathrm{SM}^{1}\right)$ showed an adequate fit to the data (see Table 2). However, after deleting three non-significant paths (from conscientiousness and agreeableness to negative alcohol-related consequences, and from agreeableness to

\footnotetext{
${ }^{1}$ The Supplementary Material can be found by accessing the online version of this paper at http://dx.doi.org and by entering doi: ...
} 
alcohol use), the fit indices improved slightly (see Table 2). The final model is presented in Figure 1, and the indirect effects and total effects are presented in Table 3 and Table 4, respectively.

Within the model, low conscientiousness was associated with higher enhancement motives and antisocial behavior which were, in turn, related to greater alcohol use and negative alcohol-related consequences. Enhancement motives were also a significant mediator of the associations between extraversion and alcohol outcomes. Antisocial behavior also mediated the associations of low agreeableness with alcohol outcomes. Finally, coping motives significantly mediated the associations between emotional stability and alcohol outcomes, such that low emotional stability was associated with higher coping motives which were, in turn, related to greater alcohol use and negative alcohol-related consequences.

\subsection{Model Invariance Across Countries}

Fit indices for model invariance remained adequate after performing multi-group analysis (see Table 2, MG1). However, results for the fully constrained model (MG2) suggested that this model was not invariant across countries $(\Delta \mathrm{CFI}=.029$ [i.e., greater than the recommended cut-off of .01$], \triangle \mathrm{RMSEA}=.002$ ). To identify an invariant model, we identified the path with the greatest contribution to reducing model fit within the fully constrained model (MG2). Once we identified this path and allowed it to be freely estimated (i.e., constraint number 23: quantity on age), we identified the next path with the greatest contribution at reducing model fit (MG3; constraint number 28: emotional stability with conscientiousness). We repeated this procedure until we obtained a $\Delta \mathrm{CFI} \leq .010$, compared with the baseline model (MG1; MG7).

In the final multi-group model, all associations were constrained between countries except for two correlations (between emotional stability and 
conscientiousness; between coping motives and enhancement motives) and two paths associated with age as a covariate (from age to quantity and from age to negative alcohol-related consequences). Further, a third path was not constrained, between agreeableness and antisocial behavior, indicating a moderated mediation relationship in the deviance proneness pathway. Thus, the pathway between agreeableness and alcohol outcomes, via antisocial behavior, was explored across countries in model MG7. Although agreeableness was negatively associated with antisocial behavior in all three countries, the magnitude of the effect was somewhat greater in the U.S. ( $\beta=-.277$ [$.347,-.208])$ and Argentina $(\beta=-.254[-.401,-.108])$ than it was in Spain $(\beta=-.179[-$ $.302,-.056])$. Although the indirect effect of agreeableness on negative alcohol-related consequences was significant in all three countries, agreeableness was only significantly related to alcohol use through antisocial behavior in the U.S. subsample (see Table 5).

\subsection{Model Invariance across Gender Groups}

We tested if the final model (M1) was invariant between gender groups. The multi-group analysis showed adequate fit (see Table 2, MG1B). The addition of constraints between the paths of the two groups (MG2B) resulted on a $\triangle \mathrm{CFI}$ and $\triangle$ RMSEA of .007. Consequently, the model can be considered invariant across gender.

\section{Discussion}

The present study aimed to replicate three personality pathways to alcohol use and alcohol-related problems found in a previous prospective study (Mezquita et al., 2014) in a large sample of young adults from the U.S., Argentina and Spain. As hypothesized, our results supported the existence of the three etiological pathways (i.e., positive affect regulation, negative affect regulation and deviance proneness personality pathways; Sher et al., 2005) in a comprehensive model.

In the positive affect regulation pathway, extraversion and low 
conscientiousness were mainly related to alcohol use through enhancement drinking motives (Kuntsche et al., 2008; Mezquita et al., 2014, 2010; Stewart et al., 2001). In the negative affect regulation pathway, low emotional stability or neuroticism was mainly associated with alcohol-related problems through coping drinking motives, which is in line with previous findings (Blevins et al., 2016; Mezquita et al., 2014, 2010). Finally, low agreeableness and low conscientiousness were related to both alcohol use and negative alcohol-related consequences through antisocial behavior, which supports the existence of the deviance proneness pathway (Finn et al., 2000; Mezquita et al., 2014). Our results replicated previous evidence about the mediational effect of drinking motives and antisocial behavior in the associations between personality domains and different alcohol outcomes (Mezquita et al., 2014). However, unlike the study of Mezquita et al. (2014), our results suggest partial, instead of full, mediation for the associations between low emotional stability and negative alcohol-related consequences, and extraversion and conscientiousness with alcohol use and negative alcohol-related consequences. Discrepancies between studies could be due to their longitudinal versus cross-sectional nature.

Regarding the association between drinking motives and alcohol-related outcomes, the direct effect of coping motives on negative alcohol-related consequences was stronger than the one involving enhancement drinking motives, while the indirect effect of enhancement on negative alcohol-related consequences was stronger than the one involving coping motives. These results are consistent with the notion of coping motives underlying the most maladaptive pattern of alcohol use (Cooper et al., 2016) and implying greater risk for developing adverse consequences, over and above what is explained by alcohol consumption. Additionally, the link between antisocial behavior 
and alcohol use and negative alcohol-related consequences, was similar to previous studies (Mezquita et al., 2014).

The second aim of the study was to examine the invariance of the model across countries and gender. We found that personality etiological pathways model of alcohol use and negative alcohol-related consequences was invariant across gender. However, some notable differences between countries arose. Although agreeableness was indirectly related to negative alcohol-related consequences through antisocial behavior in all three countries, which supports the existence of the deviance proneness pathway across countries, its indirect effect on alcohol use was not significant in Argentina and Spain. This result could be explained, at least partially, by differences in the legal age to buy alcohol across countries (18 in Argentina and Spain, but 21 in the U.S.). Therefore, buying alcohol might be considered less normative and more deviant for participants from the U.S. (majority of college students are underage), compared to those from Argentina or Spain which, in turn, may enhance the relationship between alcohol use and personality characteristics of (low) agreeableness and antisocial behavior.

\subsection{Limitations}

The present study has some limitations. First, its cross-sectional nature impedes our ability to make causal inferences between variables. Thus, we were unable to explore if changes in drinking motives and antisocial behavior mediated the relationship between changes in personality and alcohol outcomes. This might be particularly important within the negative affect regulation pathway, as previous studies have suggested that coping motives mediate the association between changes in neuroticism, low conscientiousness and impulsivity and alcohol problems in young adults (Littlefield et al., 2010a, 2010b). Second, our samples were composed of college students and, therefore, may not generalize to the broader population of young adults. Third, the ABS 
was translated from Spanish into English and, despite showing good internal consistency and non-prominent DIF across countries, more psychometric studies with English-speaking populations are needed. Fourth, measures of careless responding or insufficient effort responding (Ward et al., 2017; Ward and Pond, 2015) were not included in the online survey. Fifth, we focused on the influence of personality, motives and antisocial behavior on alcohol outcomes. However, other variables could be considered within the etiological pathways proposed by Sher et al. (2005), and it may be worth it to include them in more comprehensive models (e.g., deviant peers, maltreatment, parental history of alcoholism; Edwards et al., 2015; Kendler et al., 2011, 2016; Mezquita et al., 2014).

\subsection{Clinical Implications and Conclusions}

Sher et al. (2005) proposed a model in which personality characteristics play a prominent role in the etiology of alcohol use and misuse. This model includes different, but not mutually exclusive, pathways to alcohol use and misuse. The present study shows that, despite some minor differences among countries, this model may be generalized to young adults from the U.S., Argentina and Spain. Moreover, the model was invariant between gender groups. Previous personality-targeted interventions with adolescents showed auspicious positive effects at reducing alcohol use and alcoholrelated problems (Conrod et al., 2013; Newton et al., 2016; O'Leary-Barrett et al., 2016). Accordingly, our results suggest that similar, but adapted, interventions might be useful at preventing alcohol use and alcohol-related problems in college students, at least from the U.S., Argentina and Spain. 


\section{References}

Adams, Z.W., Kaiser, A.J., Lynam, D.R., Charnigo, R.J., Milich, R., 2012. Drinking motives as mediators of the impulsivity-substance use relation: Pathways for negative urgency, lack of premeditation, and sensation seeking. Addict. Behav. 37, 848-855. https://doi.org/10.1016/j.addbeh.2012.03.016

Bentler, P.M., 2006. EQS 6 structural equations program manual. Multivariate Software Inc, Encino, CA.

Blevins, C.E., Abrantes, A.M., Stephens, R.S., 2016. Motivational pathways from antecedents of alcohol use to consequences: a structural model of using alcohol to cope with negative affect. Am. J. Drug Alcohol Abus. 42, 395-403. https://doi.org/10.3109/00952990.2016.1141915

Bravo, A.J., Pearson, M.R., 2017. In the process of drinking to cope among college students: An examination of specific vs. global coping motives for depression and anxiety symptoms. Addict. Behav. 73, 94-98.

https://doi.org/10.1016/j.addbeh.2017.05.001

Bravo, A.J., Pearson, M.R., Pilatti, A., Mezquita, L., Ibáñez, M.I., Ortet, G., 2018a. Ruminating in English, ruminating in Spanish. Psychometric evaluation and validation of the Ruminative Thought Style Questionnaire in Spain, Argentina, and USA. Eur. J. Psychol. Assess. 1-12. https://doi.org/10.1027/1015-5759/a000465

Bravo, A.J., Pilatti, A., Pearson, M.R., Mezquita, L., Ibáñez, M.I., Ortet, G., 2018b. Depressive symptoms, ruminative thinking, drinking motives, and alcohol outcomes: A multiple mediation model among college students in three countries. Addict. Behav. 76, 319-327. https://doi.org/10.1016/j.addbeh.2017.08.028

Bravo, A.J., Pearson, M.R., Stevens, L.E., Henson, J.M., 2016. Depressive symptoms and alcohol-related problems among college students: A moderated-mediated 
model of mindfulness and drinking to cope. J. Stud. Alcohol Drugs 77, 661-666. https://doi.org/10.15288/jsad.2016.77.661

Brown, T.A., 2015. Confirmatory factor analysis for applied research, 2nd ed. Guilford Press, New York.

Caneto, F., Cupani, M., Pilatti, A., 2014. Propiedades psicométricas del Cuestionario de Motivos de Consumo de Alcohol para Argentina. Rev. Psicol. 23, 21-32. https://doi.org/10.5354/0719-0581.2014.32871

Chen, F.F., 2007. Sensitivity of goodness of fit indexes to lack of measurement invariance. Struct. Equ. Model. A Multidiscip. J. 14, 464-504. https://doi.org/10.1080/10705510701301834

Cheung, G., Rensvold, R., 2002. Evaluating goodness-of-fit indexes for testing measurement invariance. Struct. Equ. Model. 9, 233-255.

Cohen, J., 1992. A power primer. Psychol. Bull. 110, 155-159.

Collins, R.L., Marlatt, G.A., Parks, G. a, Marlatt, G.A., 1985. Social determinants of alcohol consumption: The effects of social interaction and model status on the selfadministration of alcohol. J. Consult. Clin. Psychol. 53, 189-200. https://doi.org/10.1037/0022-006X.53.2.189

Conrod, P.J., O’Leary-Barrett, M., Newton, N., Topper, L., Castellanos-Ryan, N., Mackie, C., Girard, A., 2013. Effectiveness of a selective, personality-targeted prevention program for adolescent alcohol use and misuse: a cluster randomized controlled trial. JAMA psychiatry 70, 334-42. https://doi.org/10.1001/jamapsychiatry.2013.651

Cooper, M.L., 1994. Motivations for alcohol use among adolescents: Development and validation of a four-factor model. Psychol. Assess. 6, 117-128.

Cooper, M.L., Kuntsche, E., Levitt, A., Barber, L.L., Wolf, S., 2016. Motivational 
models of substance use: A review of theory and research on motives for using alcohol, marijuana, and tobacco, in: The Oxford Handbook of Substance Use and Substance Use Disorders: Volume 1. Oxford University Press, New York, pp. 375421. https://doi.org/10.1093/oxfordhb/9780199381678.013.017

Cooper, M.L., Russell, M., Skinner, J.B., Windle, M., 1992. Development and validation of a three-dimensional measure of drinking motives. Psychol. Assess. 4, $123-132$.

Coskunpinar, A., Dir, A.L., Cyders, M.A., 2013. Multidimensionality in impulsivity and alcohol use: A meta-analysis using the UPPS model of impulsivity. Alcohol. Clin. Exp. Res. 37, 1441-1450. https://doi.org/10.1111/acer.12131

Couture, M., Stewart, S.H., Cooper, M.L., Kuntsche, E., Connor, R.M.O., Sean, P., 2017. The DRINC (Drinking Reasons Inter-National Collaboration) project: Rationale and protocol for a cross-national study of drinking motives in undergraduates. Int. J. Alcohol Drug Res. 6, 7-18.

https://doi.org/10.7895/ijadr.v6i1.239

Cox, W.M., Klinger, E., 2004. A Motivational Model of Alcohol Use (MMAU): Determinants of use and change., in: Handbook of Motivational Counseling: Concepts, Approaches, and Assessment. John Wiley \& Sons Ltd, New York, NY US, pp. 121-138.

Cox, W.M., Klinger, E., 1988. A motivational model of alcohol use. J. Abnorm. Psychol. 97, 168-180.

Edwards, A.C., Gardner, C.O., Hickman, M., Kendler, K.S., 2015. A prospective longitudinal model predicting early adult alcohol problems: Evidence for a robust externalizing pathway. Psychol. Med. 1-12. https://doi.org/10.1017/S0033291715002457 
Efron, B., Tibshirani, R.J., 1993. An introduction to the bootstrap. Chapman \& Hall/CRC, New York.

Erceg-Hurn, D., Mirosevich, V.M., 2008. Modern robust statistical methods: an easy way to maximise the accuracy and power of your research . Am. Psychol. 63, 591601.

Finn, P.R., Sharkansky, E.J., Brandt, K.M., Turcotte, N., 2000. The effects of familial risk, personality, and expectancies on alcohol use and abuse. J. Abnorm. Psychol. $109,122-133$.

Fritz, M.S., MacKinnon, D.P., 2007. Required sample size to detect the mediated effect. Psychol. Sci. 18, 233-239. https://doi.org/10.1111/j.1467-9280.2007.01882.x

Goldstein, A.L., Flett, G.L., Wekerle, C., 2010. Child maltreatment, alcohol use and drinking consequences among male and female college students: An examination of drinking motives as mediators. Addict. Behav. 35, 636-639.

Grant, B.F., Saha, T.D., June Ruan, W., Goldstein, R.B., Patricia Chou, S., Jung, J., Zhang, H., Smith, S.M., Pickering, R.P., Huang, B., Hasin, D.S., 2016.

Epidemiology of DSM-5 drug use disorder results from the national epidemiologic survey on alcohol and related conditions-III. JAMA Psychiatry 73, 39-47. https://doi.org/10.1001/jamapsychiatry.2015.2132

Hakulinen, C., Elovainio, M., Batty, G.D., Virtanen, M., Kivimäki, M., Jokela, M., 2015. Personality and alcohol consumption: Pooled analysis of 72,949 adults from eight cohort studies. Drug Alcohol Depend. 151, 110-114. https://doi.org/10.1016/j.drugalcdep.2015.03.008

Hawkins, J.D., Catalano, R.F., Arthur, M.W., 2002. Promoting science-based prevention in communities. Addict. Behav. 27, 951-976. https://doi.org/10.1016/S0306-4603(02)00298-8 
Hingson, R., Zha, W., Smyth, D., 2017. Magnitude and trends in heavy episodic drinking, alcohol-impaired driving, and alcohol-related mortality and overdose hospitalizations among emerging adults of college ages 18-24 in the United States, 1998-2014. J. Stud. Alcohol Drugs 78, 540-548.

https://doi.org/10.15288/jsad.2017.78.540

Hu, L.T., Bentler, P.M., 1999. Cutoff criteria for fit indexes in covariance structure analysis: Conventional criteria versus new alternatives. Struct. Equ. Model. 6, 155. https://doi.org/10.1080/10705519909540118

IARD, 2016. Drinking guidelines: General population. Retrieved from http://www.iard.org/policy-tables/drinking-guidelines-general-population

Kendler, K.S., Gardner, C.O., Prescott, C.A., 2011. Toward a comprehensive developmental model for alcohol use disorders in men. Twin Res. Hum. Genet. 14, $1-15$.

Kendler, K.S., Ohlsson, H., Edwards, A.C., Sundquist, J., Sundquist, K., 2016. A developmental model for alcohol use disorders in Swedish men. Psychol. Med. 46, 2759-2770. https://doi.org/10.1017/S0033291716001409

Kotov, R., Gamez, W., Schmidt, F., Watson, D., 2010. Linking “Big” personality traits to anxiety, depressive, and substance use disorders: A meta-analysis. Psychol. Bull. $136,768-821$.

Kuntsche, E., Kuntsche, S., 2009. Development and validation of the Drinking Motive Questionnaire Revised Short Form (DMQ-R SF). J. Clin. child Adolesc. Psychol. 38, 899-908. https://doi.org/10.1080/15374410903258967

Kuntsche, E., von Fischer, M., Gmel, G., 2008. Personality factors and alcohol use: A mediator analysis of drinking motives. Pers. Individ. Dif. 45, 796-800. https://doi.org/10.1016/j.paid.2008.08.009 
Littlefield, A.K., Sher, K.J., Wood, P.K., 2010a. Do changes in drinking motives mediate the relation between personality change and "maturing out" of problem drinking? J. Abnorm. Psychol. 119, 93-105.

Littlefield, A.K., Sher, K.J., Wood, P.K., 2010b. A personality-based description of maturing out of alcohol problems: Extension with a Five-Factor model and robustness to modeling challenges. Addict. Behav. 35, 948-954.

Mackinnon, S.P., Couture, M., Cooper, M.L., Kuntsche, E., Connor, R.M.O., Stewart, S.H., THE_DRINC_TEAM, 2017. Cross-cultural comparisons of drinking motives in 10 countries: Data from the DRINC project. Drug Alcohol Rev. 36, 721-730. https://doi.org/10.1111/dar.12464

Merrill, J.E., Wardell, J.D., Read, J.P., 2014. Drinking motives in the prospective prediction of unique alcohol-related consequences in college students. J. Stud. Alcohol Drugs 75, 93-102.

Meyer, J.P., 2014. Applied Measurement with JMetrik. Taylor \& Francis, New York.

Mezquita, L., Camacho, L., Ibáñez, M.I., Villa, H., Moya-Higueras, J., Ortet, G., 2015. Five-Factor Model and alcohol outcomes: Mediating and moderating role of alcohol expectancies. Pers. Individ. Dif. 74, 29-34. https://doi.org/10.1016/j.paid.2014.10.002

Mezquita, L., Ibáñez, M.I., Moya-Higueras, J., Villa, H., Arias, B., Fañanás, L., Ortet, G., 2018. Psychometric properties of Drinking Motives Questionnaire-Revised (DMQ-R) in Spanish adolescents. Eur. J. Psychol. Assess. 34, 145-153. https://doi.org/10.1027/1015-5759/a000319

Mezquita, L., Ibáñez, M.I., Moya, J., Villa, H., Ortet, G., 2014. A longitudinal examination of different etiological pathways to alcohol use and misuse. Alcohol. Clin. Exp. Res. 38, 1770-9. https://doi.org/10.1111/acer.12419 
Mezquita, L., Stewart, S.H., Ibáñez, M.I., Ruipérez, M.A., Villa, H., Moya, J., Ortet, G., 2011. Drinking motives in clinical and general populations. Eur. Addict. Res. 17, 250-261. https://doi.org/10.1159/000328510

Mezquita, L., Stewart, S.H., Kuntsche, E., Grant, V. V, 2016. Cross-cultural examination of the five-factor model of drinking motives in Spanish and Canadian undergraduates. Adicciones 28, 215-220.

https://doi.org/http://dx.doi.org/10.20882/adicciones.822

Mezquita, L., Stewart, S.H., Ruipérez, M.A., 2010. Big-five personality domains predict internal drinking motives in young adults. Pers. Individ. Dif. 49, 240-245. https://doi.org/10.1016/j.paid.2010.03.043

Mohr, C.D., Armeli, S., Tennen, H., Temple, M., Todd, M., Clark, J., Carney, M.A., 2005. Moving beyond the keg party: A daily process study of college student drinking motivations. Psychol. Addict. Behav. 19, 392-403. https://doi.org/10.1037/0893-164X.19.4.392

Mokdad, A.H., Forouzanfar, M.H., Daoud, F., Mokdad, A.A., El Bcheraoui, C., Moradi-Lakeh, M., ... Murray, C.J.L., 2016. Global burden of diseases, injuries, and risk factors for young people's health during 1990-2013: A systematic analysis for the Global Burden of Disease Study 2013. Lancet 387, 2383-2401. https://doi.org/10.1016/S0140-6736(16)00648-6

Morizot, J., 2014. Construct validity of adolescents' self-reported big five personality traits: importance of conceptual breadth and initial validation of a short measure. Assessment 21, 580-606. https://doi.org/10.1177/1073191114524015

Muthén, L.K., Muthén, B.O., n.d. Mplus. User's guide. Fifth edition. Muthén \& Muthén, Los Angeles, CA.

National Plan of Drugs, 2015. Encuesta Domiciliaria (EDADES) 2013-2014. National 
Plan of Drugs, Madrid.

Newton, N.C., Conrod, P.J., Slade, T., Carragher, N., Champion, K.E., Barrett, E.L., Kelly, E. V, Nair, N.K., Stapinski, L., Teesson, M., 2016. The long-term effectiveness of a selective, personality-targeted prevention program in reducing alcohol use and related harms: a cluster randomized controlled trial. J. Child Psychol. Psychiatry 57, 1056-1065. https://doi.org/10.1111/jcpp.12558

NIAAA, 2015. College Drinking. NIAAA Newsletter. Retrieved from http://pubs.niaaa.nih.gov/publications/CollegeFactSheet/CollegeFactSheet.pdf

O’Hara, R.E., Boynton, M.H., Scott, D.M., Armeli, S., Tennen, H., Williams, C., Covault, J., 2014. Drinking to cope among african american college students: An assessment of episode-specific motives. Psychol. Addict. Behav. 28, 671-681. https://doi.org/10.1037/a0036303

O’Leary-Barrett, M., Castellanos-Ryan, N., Pihl, R.O., Conrod, P.J., 2016. Mechanisms of personality-targeted intervention effects on adolescent alcohol misuse, internalizing and externalizing symptoms. J. Consult. Clin. Psychol. 84, 1-15. https://doi.org/10.1037/ccp0000082

Ortet, G., Martínez, T., Mezquita, L., Morizot, J., Ibáñez, M.I., 2017. Big Five Personality Trait Short Questionnaire: Preliminary validation with Spanish adults. Span. J. Psychol. 20, E7. https://doi.org/10.1017/sjp.2017.8

Pilatti, A., Read, J.P., Caneto, F., 2016. Validation of the Spanish version of the Young Adult Alcohol Consequences Questionnaire (S-YAACQ). Psychol. Assess. 28, e49-e61. https://doi.org/10.1037/pas0000140

Read, J.P., Kahler, C.W., Strong, D.R., Colder, C.R., 2006. Development and preliminary validation of the young adult alcohol consequences questionnaire. J. Stud. Alcohol 67, 169-177. https://doi.org/10.15288/jsa.2006.67.169 
Rodríguez-Martos, A., Gual, A., Llopis, J.J., 1999. The "standard drink unit" as a simplified recording system of alcohol consumption and its measurement in Spain. Med. Clin. (Barc). 112, 446-450.

Room, R., Babor, T., Rehm, J., 2005. Alcohol and public health. Lancet 365, 519-530.

Ruiz, M.A., Pincus, A.L., Dickinson, K.A., 2003. NEO PI-R predictors of alcohol use and alcohol-related problems. J. Pers. Assess. 81, 226-236.

Secretariat of Integral Policies on Drugs of the Argentine Nation, 2017. Estudio nacional en población de 12 a 65 años, sobre el consumo de sustancias psicoactivas. Sedronar, Argentina.

Sher, K.J., Grekin, E.R., Williams, N.A., 2005. The development of alcohol use disorders. Annu. Rev. Clin. Psychol. 1, 493-523.

Studer, J., Baggio, S., Mohler-Kuo, M., Dermota, P., Daeppen, J.-B., Gmel, G., 2014. Differential association of drinking motives with alcohol use on weekdays and weekends. Psychol. Addict. Behav. 28, 651-658. https://doi.org/10.1037/a0035668

Vernig, P.M., Orsillo, S.M., 2015. Drinking motives and college alcohol problems: A prospective study. J. Subst. Use 20, 340-346. https://doi.org/10.3109/14659891.2014.923053

Ward, M.K., Meade, A.W., Allred, C.M., Pappalardo, G., Stoughton, J.W., 2017. Careless response and attrition as sources of bias in online survey assessments of personality traits and performance. Comput. Human Behav. 76, 417-430. https://doi.org/10.1016/j.chb.2017.06.032

Ward, M.K., Pond, S.B., 2015. Using virtual presence and survey instructions to minimize careless responding on Internet-based surveys. Comput. Human Behav. 48, 554-568. https://doi.org/10.1016/j.chb.2015.01.070

White, H.R., Anderson, K.G., Ray, A.E., Mun, E.Y., 2016. Do drinking motives 
distinguish extreme drinking college students from their peers? Addict. Behav. 60, 213-218. https://doi.org/10.1016/j.addbeh.2016.04.011

WHO, 2014a. Global status report on alcohol and health. Geneva, Switzerland.

WHO, 2014b. WHO methods and data sources for country-level causes of death 20002012. WHO, Geneva, Switzerland.

WHO, 2013. WHO methods and data sources for country-level causes of death 20002011. Geneva, Switzerland.

Zucker, R.A., 2015. Alcohol use and the alcohol use disorders: A developmentalbiopsychosocial systems formulation covering the life course, in: Developmental Psychopathology. John Wiley \& Sons, Inc., Hoboken, NJ, USA, pp. 620-656. https://doi.org/10.1002/9780470939406.ch17

Zucker, R.A., 2008. Anticipating problem alcohol use developmentally from childhood into middle adulthood: what have we learned? Addiction 103, 100-108. https://doi.org/10.1111/j.1360-0443.2008.02179.x

Zucker, R.A., Boyd, G., Howard, J., 1994. The development of alcohol problems: exploring the biopsychosocial matrix of risk, NIAAA Research Monograph No.26. NIAAA, Rockville. 
Figure 1. Depicts the significant standardized effects of the final structural equation model $(n=1280)$. Significant associations were determined by a $99 \%$ bias-corrected unstandardized bootstrapped confidence interval (based on 10000 bootstrapped samples) that does not contain zero. The disturbances among personality dimensions (Emotional Stability with Extraversion, Emotional Stability with Conscientiousness, Emotional Stability with Agreeableness, Extraversion with Conscientiousness, Extraversion with Agreeableness, Conscientiousness with Agreeableness), drinking motives and antisocial behavior (Cope with Enhancement, Cope with Antisocial Behavior, Enhancement with Antisocial Behavior) were allowed to correlate. Path coefficients between the age effects (i.e., covariate) on all the study variables are not shown in the figure for parsimony but are available from the authors upon request. 
Table 1

Descriptive analysis.

\begin{tabular}{|c|c|c|c|c|c|c|c|c|c|c|c|c|}
\hline & \multicolumn{2}{|c|}{$\begin{array}{c}\text { U.S. }{ }^{a} \\
\mathrm{~N}=673\end{array}$} & \multicolumn{2}{|c|}{$\begin{array}{c}\text { Argentina }^{\circ} \\
\mathrm{N}=332\end{array}$} & \multicolumn{2}{|c|}{$\begin{array}{l}\text { Spain }^{c} \\
N=275\end{array}$} & \multirow{2}{*}{$\frac{\mathrm{a}-\mathrm{b}}{d}$} & \multirow{2}{*}{$\frac{\mathrm{a}-\mathrm{c}}{d}$} & \multirow{2}{*}{$\frac{\mathrm{b}-\mathrm{c}}{d}$} & \multicolumn{3}{|c|}{$\begin{array}{c}\text { Total sample } \\
\mathrm{N}=1280\end{array}$} \\
\hline & $\mathrm{M}$ & $\mathrm{SD}$ & $\mathrm{M}$ & SD & $\mathrm{M}$ & SD & & & & $\mathrm{M}$ & SD & $\alpha$ \\
\hline Age & 22.12 & 5.73 & 22.74 & 4.24 & 20.98 & 4.10 & -.12 & .23 & .42 & 22.04 & 5.09 & - \\
\hline Emotional Stability & 19.11 & 7.93 & 19.47 & 7.73 & 20.89 & 8.40 & -.05 & -.22 & -.18 & 19.59 & 8.01 & .85 \\
\hline Extraversion & 25.49 & 7.44 & 24.34 & 8.14 & 25.89 & 7.98 & .15 & -.05 & -.19 & 25.28 & 7.76 & .85 \\
\hline Agreeableness & 24.83 & 5.91 & 25.89 & 5.53 & 27.66 & 5.71 & -.19 & -.49 & -.31 & 25.72 & 5.87 & .71 \\
\hline Conscientiousness & 25.16 & 6.69 & 23.79 & 6.52 & 25.24 & 6.68 & .21 & -.01 & -.22 & 24.82 & 6.66 & .80 \\
\hline Enhancement Motives & 8.43 & 3.33 & 7.45 & 3.15 & 7.67 & 3.18 & .30 & .23 & -.07 & 8.01 & 3.28 & .78 \\
\hline Coping Motives & 6.11 & 3.21 & 5.51 & 2.79 & 4.61 & 2.15 & .20 & .55 & .36 & 5.63 & 2.96 & .83 \\
\hline Antisocial Behavior & 45.20 & 13.87 & 44.15 & 8.13 & 42.66 & 9.08 & .09 & .22 & .17 & 44.38 & 11.70 & .95 \\
\hline Quantity & 88.35 & 105.54 & 95.31 & 117.20 & 79.25 & 84.51 & -.06 & .10 & .16 & 88.20 & 104.71 & - \\
\hline Frequency & 5.88 & 5.49 & 5.82 & 4.71 & 6.44 & 5.30 & .01 & -.10 & -.12 & 5.98 & 5.26 & - \\
\hline Binge Drinking & 1.95 & 3.19 & 1.58 & 2.59 & 2.10 & 3.23 & .13 & -.05 & -.18 & 1.89 & 3.06 & - \\
\hline Negative Alcohol-related Consequences & 7.28 & 8.50 & 8.95 & 7.70 & 9.04 & 7.70 & -.21 & -.22 & -.01 & 8.09 & 8.17 & .93 \\
\hline
\end{tabular}

Note. Cohen's $d$ values of $.20, .50$ and .80 correspond to small, medium and large effect sizes, respectively (Cohen, 1992). 
Table 2

Invariance testing results of the structural equation model across countries and gender

\begin{tabular}{|c|c|c|c|c|c|c|c|c|c|c|c|c|}
\hline & \multicolumn{12}{|c|}{ Mediation Model } \\
\hline & & \multicolumn{6}{|c|}{ Overall Fit Indices } & \multicolumn{5}{|c|}{ Comparison Fit Indices } \\
\hline & & $\chi^{2}$ & $d f$ & CFI & TLI & RMSEA & SRMR & $\begin{array}{c}\text { Model } \\
\text { Comparison }\end{array}$ & $\Delta \chi^{2}$ & $\Delta d f$ & $\Delta \mathrm{CFI}$ & $\triangle$ RMSEA \\
\hline M0 & Hypothesized Model & $101.190 * *$ & 25 & .977 & .939 & $.049(.039 .059)$ & .031 & --- & --- & --- & --- & --- \\
\hline M1 & Final Model & $102.924 * *$ & 28 & .977 & .946 & $.046(.036 .055)$ & .031 & M1 vs. M0 & 1.734 & 3 & 0 & -.003 \\
\hline & \multicolumn{12}{|c|}{ Mediation Model Across Countries } \\
\hline & & \multicolumn{6}{|c|}{ Overall Fit Indices } & \multicolumn{5}{|c|}{ Comparison Fit Indices } \\
\hline & & $\chi^{2}$ & $d f$ & CFI & TLI & RMSEA & SRMR & $\begin{array}{c}\text { Model } \\
\text { Comparison }\end{array}$ & $\Delta \chi^{2}$ & $\Delta d f$ & $\Delta \mathrm{CFI}$ & $\triangle$ RMSEA \\
\hline MG1 & Unconstrained Model & $246.709 * *$ & 92 & .955 & .904 & $.063(.053 .072)$ & .041 & --- & --- & --- & --- & --- \\
\hline MG2 & Full Constrained Model+ & $417.508^{* *}$ & 162 & .926 & .910 & $.061(.054 .068)$ & .067 & MG2 vs MG1 & $170.799 * *$ & 70 & -.029 & -.002 \\
\hline MG3 & $\begin{array}{l}\text { Full Constrained Model less } \\
\text { Constraint } 23\end{array}$ & $393.976^{* *}$ & 160 & .933 & 917 & $.059(.051 .066)$ & .067 & MG3 vs MG1 & $147.267 * *$ & 68 & -.022 & -.004 \\
\hline MG4 & $\begin{array}{l}\text { Full Constrained Model less } \\
\text { Constraints } 23,28\end{array}$ & $375.866^{* *}$ & 158 & .937 & 921 & $.057(.049 .064)$ & .065 & MG4 vs MG1 & $129.157 * *$ & 66 & -.018 & -.006 \\
\hline MG5 & $\begin{array}{l}\text { Full Constrained Model less } \\
\text { Constraints } 23,28,26\end{array}$ & $364.104 * *$ & 156 & .940 & .924 & $.056(.048 .063)$ & .064 & MG5 vs MG1 & $117.385 * *$ & 64 & -.015 & -.007 \\
\hline MG6 & $\begin{array}{l}\text { Full Constrained Model less } \\
\text { Constraints } 23,28,26,15\end{array}$ & $353.489 * *$ & 154 & .943 & 926 & $.055(.048 .063)$ & .060 & MG6 vs MG1 & $106.780 * *$ & 62 & -.012 & -.008 \\
\hline \multirow[t]{4}{*}{ MG7 } & $\begin{array}{l}\text { Full Constrained Model less } \\
\text { Constraints } 23,28,26,15,33\end{array}$ & $344.594 * *$ & 152 & .945 & .928 & $.054(.047 .062)$ & .058 & MG7 vs MG1 & $97.885^{*}$ & 60 & -.010 & -.009 \\
\hline & \multicolumn{12}{|c|}{ Mediation Model Across Gender } \\
\hline & & \multicolumn{6}{|c|}{ Overall Fit Indeces } & \multicolumn{5}{|c|}{ Comparison Fit Indices } \\
\hline & & $\chi^{2}$ & $d f$ & CFI & TLI & RMSEA & SRMR & & $\Delta \chi^{2}$ & $\Delta d f$ & $\Delta \mathrm{CFI}$ & $\triangle \mathrm{RMSEA}$ \\
\hline MG1B & Unconstrained & $171.972 * *$ & 60 & .965 & .924 & $.054(.045 .064)$ & .039 & --- & --- & --- & --- & --- \\
\hline MG2B & Constrained + & $230.372 * *$ & 95 & .958 & .942 & $.047(.040 .055)$ & .045 & MG2B vs MG1B & $58.4^{*}$ & 35 & -.007 & -.007 \\
\hline
\end{tabular}

Note. ${ }^{*} p<.01 .{ }^{* *} p<.001$. +Includes the constraints in the paths observed in Figure 1, the correlations between variables and also the paths between Age and all the observable variables. The constraint 23 refers to Quantity on Age, 28 refers to Emotional Stability with Conscientiousness, 26 refers to Negative AlcoholRelated Consequences on Age, 15 refers to Antisocial Behavior on Agreeableness, and 33 refers to Coping Motives with Enhancement Motives. 
Table 3

Summary of indirect effects of personality, motives, and antisocial behavior on alcohol consumption and negative alcohol-related consequences (M1) Positive Affect Regulation Pathway

Specific indirect effects

Enhancement Motives $\rightarrow$ Alcohol Use Factor $\rightarrow$ Negative Alcohol-related Consequences $\beta$ $99 \% \mathrm{CI}$

Extraversion $\rightarrow$ Enhancement Motives $\rightarrow$ Alcohol Use Factor

Extraversion $\rightarrow$ Enhancement Motives $\rightarrow$ Negative Alcohol-related Consequences
Extraversion $\rightarrow$ Alcohol Use Factor $\rightarrow$ Negative Alcohol-related Consequences

$.062, .138$

.100

.028

Extraversion $\rightarrow$ Enhancement Motives $\rightarrow$ Alcohol Use Factor $\rightarrow$ Negative Alcohol-related Consequences

Conscientiousness $\rightarrow$ Enhancement Motives $\rightarrow$ Alcohol Use Factor

.012

Conscientiousness $\rightarrow$ Enhancement Motives $\rightarrow$ Negative Alcohol-related Consequences

$-.027$

$.003, .020$

Conscientiousness $\rightarrow$ Alcohol Use Factor $\rightarrow$ Negative Alcohol-related Consequences

$-.011$

$-.045$

$.011, .082$

Conscientiousness $\rightarrow$ Enhancement Motives $\rightarrow$ Alcohol Use Factor $\rightarrow$ Negative Alcohol-related Consequences

$-.011$

$.003, .020$

$-.046,-.007$

$-.022,-.001$

Total indirect effects

Extraversion $\rightarrow$ Negative Alcohol-related Consequences

$-.081,-.009$

*Conscientiousness $\rightarrow$ Alcohol Use Factor

.070

$-.020,-.003$

*Conscientiousness $\rightarrow$ Negative Alcohol-related Consequences

Negative Affect Regulation Pathway

Specific indirect effects

Coping Motives $\rightarrow$ Alcohol Use Factor $\rightarrow$ Negative Alcohol-related Consequences

Emotional Stability $\rightarrow$ Coping Motives $\rightarrow$ Alcohol Use Factor

Emotional Stability $\rightarrow$ Coping Motives $\rightarrow$ Negative Alcohol-related Consequences

$-.048$

$.032, .109$

$-.109$

$-.075,-.021$

Emotional Stability $\rightarrow$ Coping Motives $\rightarrow$ Alcohol Use Factor $\rightarrow$ Negative Alcohol-related Consequences

$\beta$

$-.151,-.067$

Total indirect effects

Emotional Stability $\rightarrow$ Negative Alcohol-related Consequences

Deviance Proneness Pathway

Specific indirect effects

Antisocial Behavior $\rightarrow$ Alcohol Use Factor $\rightarrow$ Negative Alcohol-related Consequences

$99 \% \mathrm{CI}$

Conscientiousness $\rightarrow$ Antisocial Behavior $\rightarrow$ Alcohol Use Factor

Conscientiousness $\rightarrow$ Antisocial Behavior $\rightarrow$ Negative Alcohol-related Consequences

.055

$-.037$

$-.043$

$-.016$

$-.058$

$\beta$

$-.058$

.050

$-.021$

$-.033$
.012, 099

$-.065,-.009$

$-.006,-.019$

$-.028,-.003$

$-.084,-.032$ $99 \%$ CI

$.013, .087$

$-.039,-.004$ $-.053,-.013$ 
Conscientiousness $\rightarrow$ Antisocial Behavior $\rightarrow$ Alcohol Use Factor $\rightarrow$ Negative Alcohol-related Consequences

Agreeableness $\rightarrow$ Antisocial Behavior $\rightarrow$ Alcohol Use Factor

Agreeableness $\rightarrow$ Antisocial Behavior $\rightarrow$ Negative Alcohol-related Consequences

Agreeableness $\rightarrow$ Antisocial Behavior $\rightarrow$ Alcohol Use Factor $\rightarrow$ Negative Alcohol-related Consequences

Agreeableness $\rightarrow$ Negative Alcohol-related Consequences

$-.058$

$-.088,-.028$

Note. Significant associations are bolded were determined by a $99 \%$ bias-corrected unstandardized bootstrapped confidence interval (based on 10,000 bootstrapped samples) that does not contain zero. *Common pathways to Deviance Proneness and Positive affect regulation. When the specific indirect effect was the same as the total indirect effect, we reported the results only once in the specific indirect effect section. 
Table 4

Summary of total effects (direct + indirect effects) of personality, motives, and antisocial behavior on alcohol consumption and negative alcohol-related consequences (MI)

\begin{tabular}{|c|c|c|c|c|}
\hline & \multicolumn{2}{|c|}{ Alcohol Use } & \multicolumn{2}{|c|}{$\begin{array}{c}\text { Negative Alcohol-related } \\
\text { Consequences }\end{array}$} \\
\hline & $\beta$ & $99 \% \mathrm{CI}$ & $\beta$ & $99 \% \mathrm{CI}$ \\
\hline Emotional Stability & -.037 & $-.065,-.009$ & -.162 & $-.218-.107$ \\
\hline Extraversion & .138 & $.059, .218$ & .070 & $.032, .109$ \\
\hline Conscientiousness & -.155 & $-.228,-.082$ & -.109 & $-.151,-.067$ \\
\hline Agreeableness & -.029 & $-.053,-.006$ & -.058 & $-.088,-.028$ \\
\hline Enhancement Motives & .239 & $.158, .320$ & .202 & $.134, .270$ \\
\hline Coping Motives & .131 & $.036, .226$ & .206 & $.128, .285$ \\
\hline Antisocial Behavior & .118 & $.030, .206$ & .232 & $.133, .332$ \\
\hline Alcohol Use & - & - & .420 & $.311, .529$ \\
\hline
\end{tabular}

Note. Significant associations are bolded and were determined by a $99 \%$ bias-corrected unstandardized bootstrapped confidence interval (based on 10,000 bootstrapped samples) that does not contain zero. 
Table 5

Indirect effects of Agreeableness on Alcohol Use and Negative Alcohol-related Consequences through Antisocial behavior in USA, Argentina and Spain (MG7)

\begin{tabular}{|c|c|c|c|c|c|c|}
\hline & \multicolumn{2}{|c|}{ USA } & \multicolumn{2}{|c|}{ Argentina } & \multicolumn{2}{|c|}{ Spain } \\
\hline & $\beta$ & $99 \% \mathrm{CI}$ & $\beta$ & $99 \% \mathrm{CI}$ & $\beta$ & $99 \% \mathrm{CI}$ \\
\hline \multicolumn{7}{|l|}{ Specific indirect effects } \\
\hline Agreeableness $\rightarrow$ Antisocial Behavior $\rightarrow$ Alcohol Use Factor & -.041 & $-.072,-.010$ & -.026 & $-.055, .004$ & -.021 & $-.043, .002$ \\
\hline Agreeableness $\rightarrow$ Antisocial Behavior $\rightarrow$ Negative Alcohol-related Consequences & -.060 & $-.097,-.022$ & -.037 & $-.071,-.002$ & -.029 & $-.057,-.001$ \\
\hline Agreeableness $\rightarrow$ Antisocial Behavior $\rightarrow$ Alcohol Use Factor $\rightarrow$ Negative Alcohol-related Consequences & -.017 & $-.029,-.004$ & -.010 & $-.021, .000$ & -.008 & $-.017, .001$ \\
\hline \multicolumn{7}{|l|}{ Total indirect effect } \\
\hline Agreeableness $\rightarrow$ Negative Alcohol-related Consequences & -.076 & $-.117,-.035$ & -.047 & $-.088,-.005$ & -.037 & $-.071,-.004$ \\
\hline
\end{tabular}

Note. Significant associations are in bold typeface for emphasis and were determined by a $99 \%$ bias-corrected unstandardized bootstrapped confidence interval (based on 10,000 bootstrapped samples) that does not contain zero 


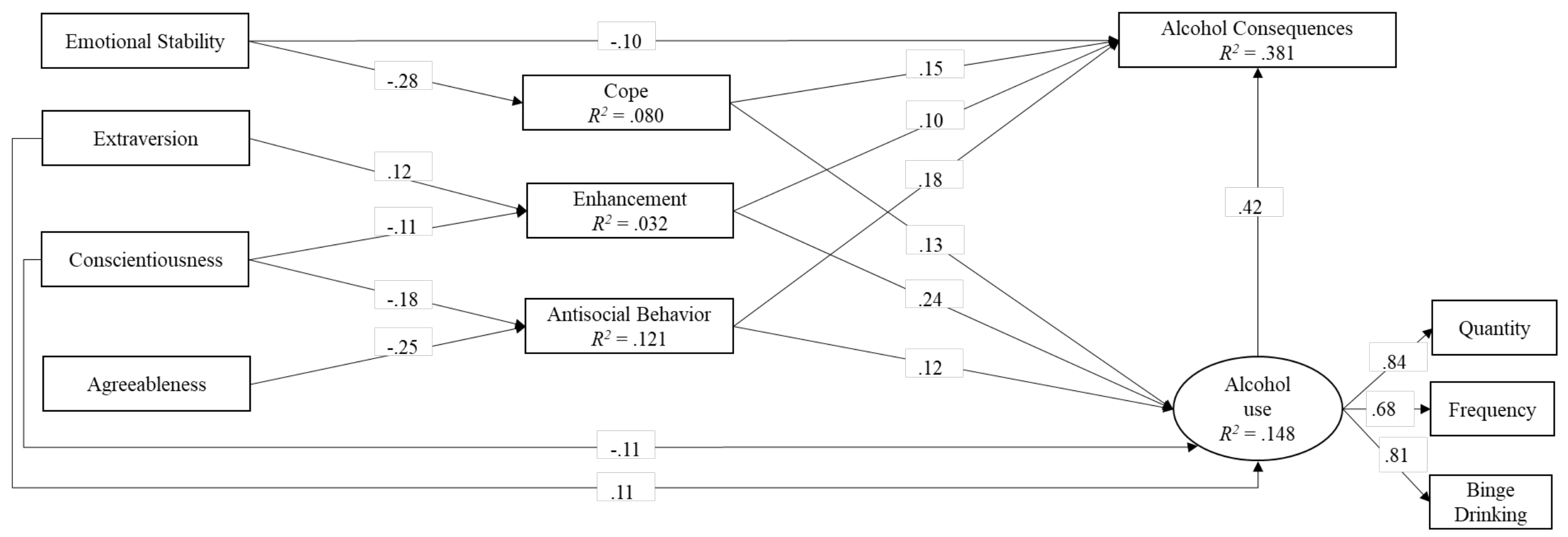




\section{Author Disclosures}

\section{Role of Funding Sources}

There was no direct funding for this study in the US. However, Dr. Pearson is supported by a career development grant (K01-AA023233) from the National Institute of Alcohol Abuse and Alcoholism (NIAAA) and Dr. Bravo is supported by a training grant (T32-AA018108) from the NIAAA. NIAAA had no role in the study design, collection, analysis or interpretation of the data, writing the manuscript, or the decision to submit the paper for publication. Data collection in Spain was supported, in part, by grants PSI2015-67766-R from the Spanish Ministry of Economy and Competitiveness, GV/2016/158 from the Autonomous Government of Valencia and UJI-A2017-18 from the Universitat Jaume I.

\section{Contributors}

Dr. Mezquita conceptualized the research questions, conducted the analyses, drafted the introduction, method, statistical analyses, results (including tables) and discussion sections. Dr. Bravo coordinated the efforts of the research team, supported the data analyses, and drafted parts of the manuscript. Dr. Pilatti, Dr. Pearson and Dr. Ortet edited parts of the introduction, analysis, results and discussion section of the first draft. Dr. Ibáñez conceptualized the research questions, draft the introduction and the discussion section and edited the other sections of the first draft. The entire team selected the measures in the assessment battery and collected all data. All authors contributed to and approved of the final manuscript.

\section{Conflict of Interest}

No conflict declared.

\section{Acknowledgments}

No acknowledgments declared. 
${ }^{*}$ Conflict of interest statement

\section{Conflict of Interest}

No conflict declared by any author. 


\section{Contributors}

Dr. Mezquita conceptualized the research questions, conducted the analyses, drafted the introduction, method, statistical analyses, results (including tables) and discussion sections. Dr. Bravo coordinated the efforts of the research team, supported the data analyses, and drafted parts of the manuscript. Dr. Pilatti, Dr. Pearson and Dr. Ortet edited parts of the introduction, analysis, results and discussion section of the first draft. Dr. Ibáñez conceptualized the research questions, draft the introduction and the discussion section and edited the other sections of the first draft. The entire team selected the measures in the assessment battery and collected all data. All authors contributed to and approved of the final manuscript. 
Supplementary Material
Click here to download Supplementary Material: DAD_SM1.docx

Supplementary Material
Click here to download Supplementary Material: DAD_SM1.docx

Click here to download Supplementary Material: DAD_SM1.docx

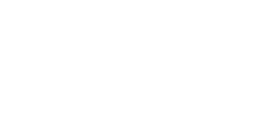

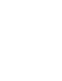

(1)

$\sqrt{3}$

(1)

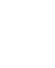

(1)

(1)

(1)

.

.

.

.

.

.

.

.

.

.

.

.

.

.

.

.

.

.

. 